\title{
The emergence of Canadian Feature Film Policy
}

\author{
By Johanna Kern
}

Spring 2000 Issue of KINEMA

DURING the 1920s and early 1930s American films regularly accounted for as much as eighty-five to ninetyfive percent of the national Canadian box office. There were quite a few attempts, already in those early decades of cinema, to boost the fortune of the national film industry and to establish production companies and studios. These, however, with a few exceptions, did not last long enough to change the picture of the American-dominated Canadian film industry. Canadians tried to fight back and win the battle for their home market. However, their efforts were doomed. When an attempt was made to prosecute the local subsidiary of the American Adolph Zukor's Famous Players... the case was thrown out by the judge for "anti-competitive behaviour"!

Many Canadian scholars tried to explain the mechanisms behind the repetitive failures of Canadian producers and filmmakers in their ongoing struggle to maintain their own film industry. They saw the reasons for the unsuccessful efforts mostly in the lack of Governmental feature film policies and in Canada's unfortunate location, right along the border of the United States and its Film Empire. Dorland says:

"In any case, it would not be until the 1960s that the making of feature film became a continuing policy issue for agencies of the federal government with fiscal and bureaucratic implications. To be sure, the extent of the government's commitment has fluctuated considerably in the period from the 1960s to the present..."

Michael Dorland presents a detailed study of the formation of Canadian feature film policy. His analysis is based on primary sources, from government records to quotes from personal interviews and press articles. Dorland gives us another angle on the relationship between culture and the state and attempts to contribute to the "'thick' policy analysis undertaking through a detailed discussion of policy in a particular period to raise some of the problems affecting cultural policy-making within increasingly transnational contexts."

Thoroughly researched, this volume clarifies the ambivalence of the historical record and might be useful reading for Canadian and other scholars.

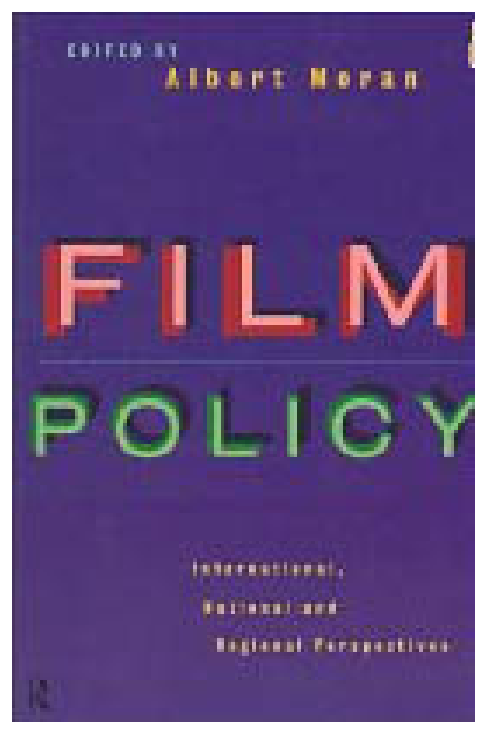

Figure 1: BY: Michael Dorland: So Close to the State/s: The Emergence of Canadian Feature Film Policy. ๆ PUBLISHER: University of Toronto Press ๆ YEAR: 2000 ๆ PAGES: 304 ๆ ISBN-13: 978-0415097918 


\section{Author Information}

Johanna KERN became an actress, after studying at the Visual Arts College in Kielce (Poland). She performed on screen and stage in Poland and West Germany. She moved to Canada in 1989 and while still acting, she wrote, directed and produced five short films. One of these, Cherries for Brian, was shown at the 1997 Raindance Film Festival in London. 